\title{
Synthesis and characterization of chitosan/potato peel powder-based hydrogel and its in vitro antimicrobial activity
}

\author{
Kulsum Neha ${ }^{1}$, Rajagopal Anitha ${ }^{1}$, Rajakannu Subashini ${ }^{1 *}$, Amirthakadeswaran Natarajan ${ }^{1}$, T. M. Sridhar $^{2}$ \\ ${ }^{1}$ Department of Biomedical Engineering, SSN College of Engineering, Chennai, India. \\ ${ }^{2}$ Department of Analytical Chemistry, University of Madras, Chennai, India.
}

\author{
ARTICLE INFO \\ Received on: $16 / 04 / 2019$ \\ Accepted on: 22/06/2019 \\ Available online: 01/09/2019 \\ Key words: \\ Hydrogels, potato peel, \\ chitosan, biocompatibility, \\ wound healing.
}

\begin{abstract}
The present work was designed to incorporating the properties of potato peel (PP) (Solanum tuberosum) in wound care with chitosan to make a hydrogel that is superior, cheaper, biocompatible, and enabling faster healing. Chitosan and PP powder-based hydrogel was synthesized with acetic acid as the solvent medium and Gluteraldehyde as the cross linker. The prepared hydrogel was characterized and tested using scanning electron microscopy, Fourier transform infrared analysis, swelling test, and antimicrobial activity test. The results of the present study demonstrated that the prepared hydrogel showed significant antimicrobial activity with effective swellability, structural, and surface characteristics. Based on the characterization studies, it is concluded that the synthesized hydrogel had shown better characteristics and can be used as a promising material for wound healing applications.
\end{abstract}

\section{INTRODUCTION}

Tissue engineering is the branch of advanced science focusing on the development, repair, and regeneration of the damaged tissues and organs which involves the concept of cells, biomaterials, biochemical factors, and engineering methodologies. Many current advances in tissue engineering have provided opportunities for wound healing. But, a number of different kinds of wound dressings, which are commercialized now-a-days, have certain important limitations like addition of antimicrobial agents. Such introduced antimicrobial agents are having cytotoxic effects, leading to delayed wound healing. Also, the wound dressings stick on to the surface of the wound and injure the newly formed epithelium. The development of resistance among the microbial flora to the existing synthetic antimicrobial agents creates a very serious risk to public health (Levy and Marshall, 2004; Mah and O' Toole et al., 2001; Mandal et al., 2009; Saga and Yamaguchi, 2009). Hence, alternative measures for the above problem should be addressed immediately, and consequently this state has led to a

"Corresponding Author

R. Subashini, Department of Biomedical Engineering, SSN College of Engineering, Chennai, India.E-mail: subashinir@ssn.edu.in re-assessment of the therapeutic use of traditional medication, such as plants and plant-based products (Basualdo et al., 2007; Mandal et al., 2010a; 2010b), including PPs, neem, turmeric, and honey which are traditionally been used for enabling superior wound healing even when their evidence is not documented. Especially, the PPs have various medicinal and nutritional value and they are the source of phenolic compounds, flavonoids, glycoalkaloids, and cell wall polysaccharides (majorly), vitamins and minerals like potassium (Friedman et al., 2005; Schieber et al., 2009). The glycoalkaloids present in PPs are toxic to microorganisms and these glycoalkaloids have beneficial properties, such as antipyretic, anti-inflammatory, and antimicrobial activities against pathogenic microbes (Friedman et al., 2005).

An attempt to overcome the limitations of wound dressings, the use of hydrogels, a three-dimensional macromolecular network of polymers in tissue-engineered wound healing is investigated. The networks of hydrogel can extensively swell up in water since, water is the major constituent of the human body system and a hydrogel, which be able to absorb large amounts of water, is considered to have huge potential when it is applied for pharmaceutical purposes (Billiet et al., 2012; Daniele et al., 2014; Hoffman et al., 2012; Wang et al., 2015; Yu et al., 2016a; 2016b). Fortunately, with the advent of various synthetic 
strategies developed and also by modifying the hydrogel polymer matrix with distinct network arrangements, enviable chemical compositions and desirable mechanical strength can be achieved. Hydrogels obtained from natural sources resist to adverse conditions like high temperature and extremes of acidic or basic environment (Chai et al., 2017). The hydrogels are prepared using the natural polymers, such as chitosan, gelatin, collagen, elastin, agarose, and alginate obtained from both plants and animals. Chitosan, a natural polymer derived from chitin, is a linear polysaccharide and hydrophilic. The chitosan-based hydrogels have shown biocompatibility, biodegradability, antimicrobial property, and non-toxicity (Sahoo et al., 2009).

Potato peel (PP), an industry waste material, is considered to be a zero-value by product. But, this inexpensive and valuable base material is used for the extraction of valuable products, such as natural antioxidants, dietary fiber, and biopolymers, due to the presence of primary and secondary metabolites, such as starch, proteins, polyphenols, lignins, and small quantities of lipids. The chemical compositions of the PP are water, protein, lipids, carbohydrates, starch and dietary fiber (Sepelev and Galoburda, 2015). There were no published reports on the antimicrobial properties of chitosan with PP powder-based hydrogel, thus the present work is considered to be of great importance in the biomedical applications. Taking inspiration from the above findings, the present work aims to incorporate the properties of $\mathrm{PP}$ in wound care with chitosan producing a hydrogel which is superior, cheaper, biocompatible, and to enable faster healing.

\section{MATERIALS AND METHODS}

\section{Chemicals}

The PPs (Solanum tuberosum) were collected from the local market of Chennai. The following are the chemicals required for the synthesis and testing of hydrogel: Chitosan powder (low molecular weight), Glacial acetic acid (99.5\% pure), Glutaraldehyde (25\% wt.), and buffer solutions with various $\mathrm{pH}$. All the chemicals used were of analytical grade and obtained from Fischer Scientific Company, Waltham, MA.

\section{Drying and powdering of PPs}

Fresh and raw potatoes were collected and the peels were removed. The removed peels were washed with normal tap water and later with de-ionized water. It was then allowed to dry for about half an hour at room temperature and the excess moisture were completely removed by placing the PPs in hot air Oven at $45^{\circ} \mathrm{C}$ for 24 hours. The dried PPs were then ground using mechanical grinder and crushed into a fine powder using mortar and pestle. The powdered material was sieved using a micron test sieve (mesh no. 400 ASTM \& BSS) to obtain a fineness of $<37$ $\mu \mathrm{m}$ and collected in an air-tight container, stored at $4^{\circ} \mathrm{C}$ until use.

\section{Preparation of chitosan/potato peel powder (ppp) hydrogels}

One gram of chitosan in three separate lots were weighed and suspended in $20.0 \mathrm{ml}$ each of $2 \%$ acetic acid at room temperature for 24 hours with constant stirring (450 rpm) to obtain pale yellow gelatinous chitosan solutions (CS). The PPP of three different amounts [0.075 g (C1), $0.1 \mathrm{~g}(\mathrm{C} 2)$, and $0.15 \mathrm{~g}$ (C3)] were dissolved in $5 \mathrm{ml}$ each of $2 \%$ aqueous acetic acid by sonicating initially for about 45 minutes, followed by continuous stirring for 3 hours $(650 \mathrm{rpm})$. Both the solutions were then mixed together by stirring continuously for $6-8$ hours at $650 \mathrm{rpm}$ to obtain viscous brown chitosan/PPP solutions. One milliliter of aqueous glutaraldehyde (1\%) solution was supplemented to all the three different samples of clear brown CS and stirred for about 5 minutes to form cross-linked chitosan/PPP hydrogels. The obtained hydrogels was dried under freeze-drier (Liotop 101L, Liobras) at $-50^{\circ} \mathrm{C}$ for 24 hours followed by freezing at $90^{\circ} \mathrm{C}$ for 5 hours. All samples were kept in glass desiccators until analysis. Figure 1(a) and (b) indicates the hydrogel of chitosan/PPP in normal and dried conditions, respectively.

\section{Scanning electron microscopy (SEM) analysis}

The hydrogel texture was examined by field emission scanning electron microscopy (FESEM) to ensure that it retains its structure or not. The dried hydrogel was cut to expose its inner structure for SEM studies. The freeze-dried sample was imaged using FEI Quanta 200F operating at a voltage of $30 \mathrm{kV}$.

\section{Fourier transform infrared spectroscopy (FTIR)}

Nature of chemical bonds or functional groups present in PPP is identified through the FTIR. Different compositions of the hydrogel $(\mathrm{C} 1, \mathrm{C} 2$, and $\mathrm{C} 3)$ were prepared and used for FTIR analysis. The gel sample was loaded in FTIR Spectroscope (PerkinElmer Spectrum Two, Waltham, MA), with a wave range of 400 to $4,000 \mathrm{~cm}^{-1}$. The spectrophotometer was being operated in the attenuated total reflection (ATR) mode.

\section{Swelling study}

The swelling study of the test samples were done at room temperature with buffer solutions of different $\mathrm{pH}$ values 4 , 7.4, and 9 and the effect of time on the percentage swellability was calculated at varying time periods of $10,20,30,40,50$, and 60 minutes at a constant $\mathrm{pH}$. The hydrogels were then drawn from solutions at varying time intervals and their wet weight were measured after first blotting with a Whatman No. 1 filter paper followed by blowing with a stream of air to eliminate the surface water and weighed right away.

The percentage of swelling (S) of cross-linked chitosan/ PPP hydrogels were studied by using Equation (1).

$$
S=((\mathrm{Ws}-\mathrm{Wd}) / \mathrm{Wd}) \times 100
$$

where Wd - dry weight of the sample in grams, Ws - wet (swollen) weight of the sample at time $t$ [The dried sample of known mass (Wd) was immersed in buffer solution at definite time period $t$ and then the prepared hydrogel was taken out from the solution, immediately wipe up with the filter paper and weighed (Ws)].
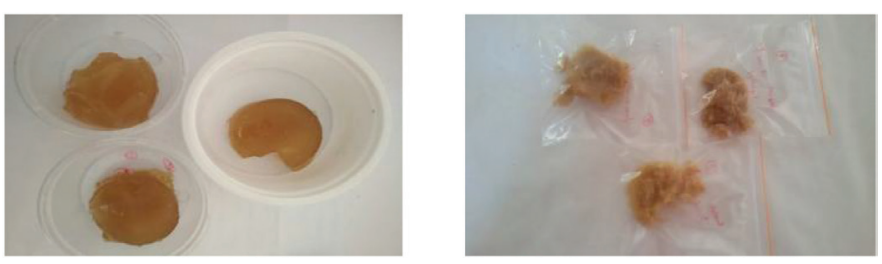

Figure 1. (a) Chitosan/ppp hydrogels. (b) Freeze dried Chitosan/ppp hydrogels. 


\section{Antimicrobial study}

\section{Microbial strains and culture conditions}

The Gram-positive strains, such as Staphylococcus aureus (ATCC 6538) and Streptococcus mutans (ATCC 31987) and Gram-negative strains, namely, Escherichia coli (ATCC 25922), Pseudomonas aeruginosa (ATCC 27853), and Salmonella typhimurium (ATCC 14028) were acquired from American Type Culture Collection, Manassas, USA. All strains were maintained on Muller-Hinton Agar (MHA) plates and stored at $4^{\circ} \mathrm{C}$, weekly once sub cultured. The inoculums were prepared by adjusting to 1 $\times 10^{8}$ colony forming units $/ \mathrm{ml}$ on comparison with $0.5 \mathrm{McF}$ arland Standards and then diluted to $1: 1,000$ ratio using sterile nutrient broth.

\section{Antimicrobial susceptibility test}

The antimicrobial activity of chitosan/PPP hydrogel was determined by agar well-diffusion method. The MHA plates were seeded with the prepared inoculum using sterile cotton swabs and the surface of the media was left to dry for about 5 minutes. Then, the hole was made with a diameter of $6 \mathrm{~mm}$ aseptically using a sterile cork borer. Twenty five microliters of test samples were placed on to each well, Ciprofloxacin $5 \mu \mathrm{g}$ per disc was used as a reference control, and 10\% DMSO was used as a negative control. The plates were incubated at $37^{\circ} \mathrm{C}$ for 24 hours. The presence of clearing zone (ZOI) around the wells was examined after 24 hours of incubation. The readings were taken in triplicates.

\section{Statistical analysis}

Values from all the experimental groups were expressed as mean $\pm \mathrm{SD}$ of three individual readings. The statistical analysis was done by SPSS software (SPSS, Version 20.0, Armonk, NY: IBM Corp., USA). The variation between all the treatment groups was analyzed by one-way analysis of variance. The significance between the control and treatment groups was determined by Duncan's multiple range test and a $p$ value $<0.05$ was considered as statically significant.

\section{RESULTS AND DISCUSSION}

\section{SEM analysis}

The FESEM images of the freeze-dried chitosan/PPP hydrogel were taken at various magnifications, viz., 1,000, 2,000, and $5,000 \times$. Figure $2 \mathrm{a}-\mathrm{c}$ shows the SEM pictures with different resolutions $(40,20$, and $5 \mu \mathrm{m})$, respectively. The freeze-dried sample under magnification of $1,000 \times$ produced a SEM image with large number of pores, indicating the formation of hydrogel. The enlarged pores varied in size about $1-200 \mu \mathrm{m}$ with an average pore size of $82 \mu \mathrm{m}$ which was determined using the Imagej software. In the present study, the SEM images of the prepared hydrogel clearly pointed out the pattern of interconnected pores, capillary channels and the cross-linked chitosan molecules around the peripheries of pores.

\section{FTIR analysis}

FTIR spectra of hydrogels were acquired in the ATR mode. The spectra of all the hydrogels of different composition $(\mathrm{C} 1, \mathrm{C} 2$, and $\mathrm{C} 3)$ were found to be similar to each other
(Fig. 3a-c) and showed only slight variation, the PPP content in the formulations alone varied. The FTIR spectrum of the crosslinked chitosan hydrogel presented in the Table 1, shows broad peak at $\sim 3,255 \mathrm{~cm}^{-1}$ reveals the $\mathrm{O}-\mathrm{H}$ stretching. The peaks at $\sim 2,150$ and $\sim 1,635$ correspond to the alkyls and alkenes, may be present in the PP.

The peak at $\sim 1,550 \mathrm{~cm}^{-1}$ is allocated to the stretching vibration of amino group of chitosan added (Anicuta et al., 2010). The peak around $\sim 1,153 \mathrm{~cm}^{-1}$ is attributed for the presence of polysaccharide content of the chitosan. The peaks at 1,093 and

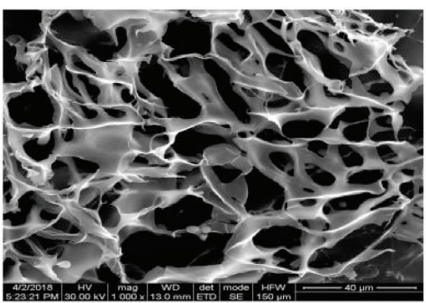

a)

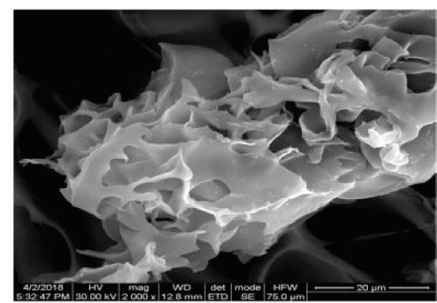

b)

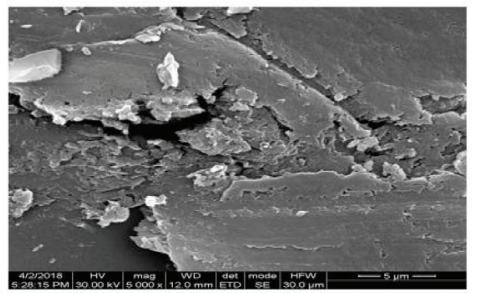

c)

Figure 2. SEM images of Chitosan/PPP hydrogel with different magnifications. (a) $1,000 \times$, (b) $2,000 \times$, and (c) 5,000× magnification.

Table 1. FT-IR peak values of different chitosan/PPP hydrogel compositions.

\begin{tabular}{|c|c|c|c|}
\hline $\begin{array}{c}\text { Name of the } \\
\text { sample }\end{array}$ & Peak values $\mathrm{cm}^{-1}$ & Bond & Functional groups \\
\hline \multirow[t]{6}{*}{$\mathrm{C} 3$} & 3,261 & OH stretching & Alcohol and phenol \\
\hline & 2,146 & $\mathrm{C} \equiv \mathrm{C}$ group & Alkynes \\
\hline & 1,634 & $\mathrm{C}=\mathrm{C}$ group & Alkenes \\
\hline & 1,550 & N-H bending & Secondary Amines \\
\hline & 1,414 & C-O stretching & Tertiary Alcohols \\
\hline & 1,093 and 1,021 & C-N stretching & Aliphatic amines \\
\hline \multirow[t]{6}{*}{$\mathrm{C} 2$} & 3,253 & O-H stretching & Alcohol and phenols \\
\hline & 2,152 & $\mathrm{C} \equiv \mathrm{C}$ group & Alkynes \\
\hline & 1,633 & $\mathrm{C}=\mathrm{C}$ group & Alkenes \\
\hline & 1,548 & $\mathrm{~N}-\mathrm{H}$ bending & Amines \\
\hline & 1,413 & C-O stretching & Tertiary alcohols \\
\hline & 1,093 and 1,022 & C-N stretching & Aliphatic amines \\
\hline \multirow[t]{6}{*}{$\mathrm{C} 1$} & 3,255 & O-H stretching & Alcohol and phenols \\
\hline & 2,144 & $\mathrm{C} \equiv \mathrm{C}$ group & Alkynes \\
\hline & 1,633 & $\mathrm{C}=\mathrm{C}$ group & Alkenes \\
\hline & 1,548 & $\mathrm{~N}-\mathrm{H}$ bending & Amines \\
\hline & 1,412 & C-O stretching & Tertiary alcohols \\
\hline & 1,092 and $1,0711,022$ & C-N stretching & Aliphatic amines \\
\hline
\end{tabular}




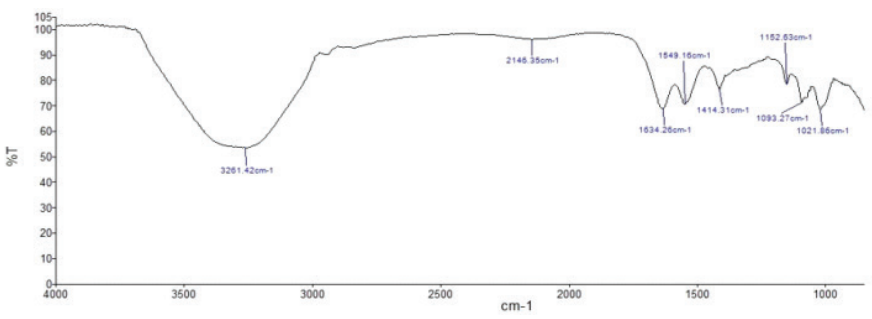

a) $\mathrm{C} 3$

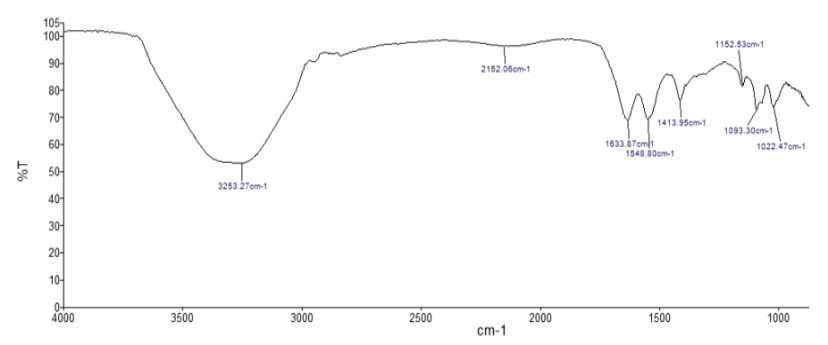

b) $\mathrm{C} 2$

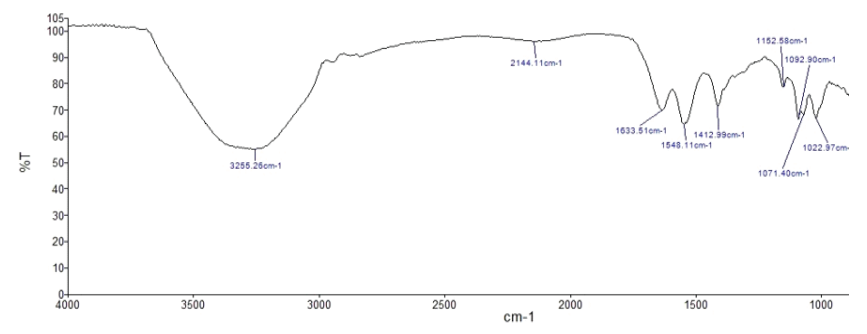

c) $\mathrm{C} 1$

Figure 3. FTIR spectra for chitosan/PPP hydrogel. (a), (b), and (c) illustrate the FTIR spectrum of hydrogels of different composition, viz., C3, C2, and C1, respectively.

$1,022 \mathrm{~cm}^{-1}$ corresponds to the $\mathrm{C}-\mathrm{N}$ stretching, which corresponds to the efficient cross-linking of chitosan hydrogel with glutaraldehyde, that formed at the amino group of chitosan (Akakuru and Isiuku, 2017).

\section{Swelling study}

\section{Effect of time}

The swelling behavior is plotted on three formulations of the hydrogel. The swelling kinetics and time dependent swelling properties of chitosan hydrogels in de-ionized water $(\mathrm{pH}$ 4) (Fig. 4a), phosphate buffer ( $\mathrm{pH}$ 7.4) (Fig. 4b), and alkaline buffer ( $\mathrm{pH}$ 9) (Fig. 4c) were tested. The results revealed that the percentage swelling of the cross-linked chitosan/ PPP-based hydrogel increases as the time increases, but near equilibrium was achieved after 50 minutes, where the swellability is decreased when compared to the initial 10 minutes. The water absorption capacity of the films ranged from $38 \%$ to $106 \%$.

This property is due to the presence of hydroxyl groups in the chitosan which is responsible for its hydrophilic nature and the flexible property of the matrix. The swellability of chitosanbased hydrogel are commonly affected by three aspects. 1. The hydrophilic nature of chitosan due to the presence of hydroxyl

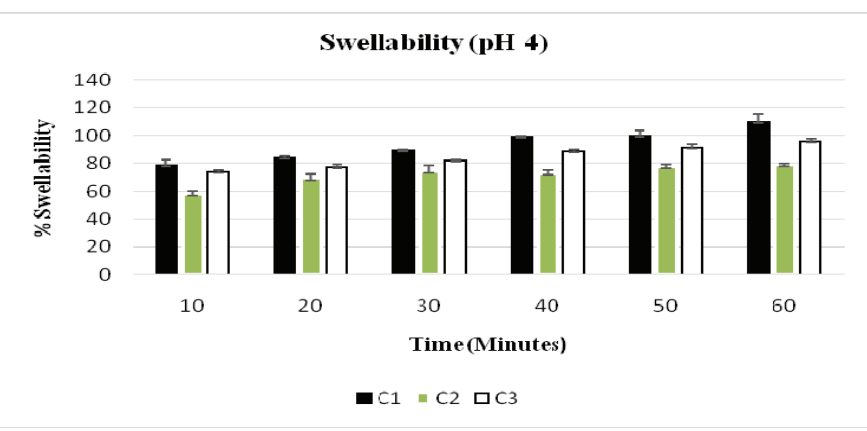

a) $\mathrm{pH} 4$

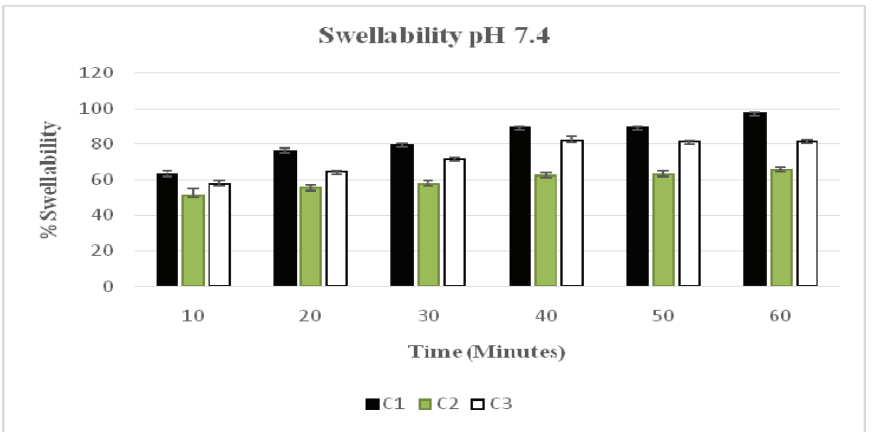

b) $\mathrm{pH} 7.4$

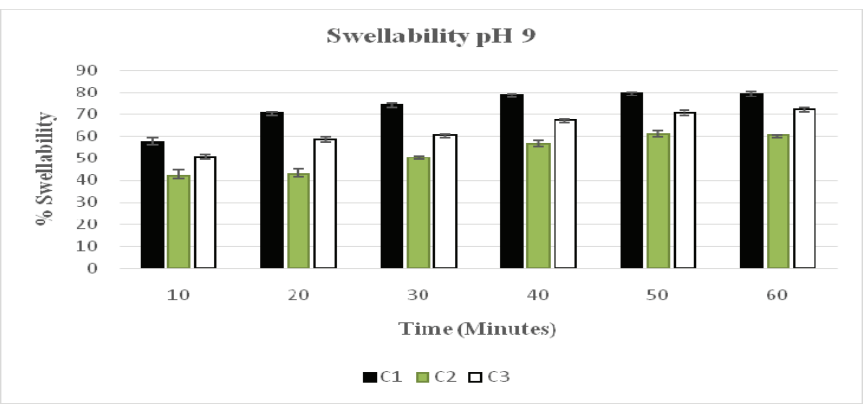

c) $\mathrm{pH} 9$

Figure 4. Swellability of chitosan/PPP hydrogel. (a) at $\mathrm{pH} 4$, (b) at $\mathrm{pH} 7.4$, and (c) at $\mathrm{pH}$ 9. Values are the mean $\pm \mathrm{SD}$ of three independent readings. $p$ value less than 0.05 was considered significant.

$(-\mathrm{OH})$ groups in its side chain. 2. Presence of amino $\left(-\mathrm{NH}_{2}\right)$ groups, which gets protonated in water, predominantly in acidic medium. 3 . Elasticity of the chitosan polymeric matrix, which allows easy diffusion of the solution (Furuike, 2017; Othman et al., 2017).

Additionally, the percentage swellability was found to be in the order of $\mathrm{C} 1>\mathrm{C} 3>\mathrm{C} 2$ at different $\mathrm{pH}$ conditions indicating that the swelling was found to be higher in hydrogels, containing higher proportions of the PP. This may be explained due to the presence of dietary fibers (cell wall polysaccharides), whereas the non-resistant starch content in the peels makes it to possess good water absorption property (Bodner and Sieg, 2009).

\section{Effect of $p H$}

Figure 5 represents the effect of $\mathrm{pH}$ on the percentage swellability of different cross-linked chitosan/PPP hydrogel formulations. The results of the present investigation demonstrated 
that the effect of percentage swellability on $\mathrm{pH}$ explained all the hydrogel formulations displayed high swellability at low $\mathrm{pH}$ than at 7.4 (neutral) and 9 (alkaline). Since, protonation of amino groups of chitosan takes place at low $\mathrm{pH}$ which leads to repulsion in the polymer chains. At high $\mathrm{pH}$ conditions, the formation of intra-molecular hydrogen bonding allows more water molecules into the gel matrix and also de-protonation of amino groups takes place that ensure repulsion in the polymer chains, which allows contraction of their polymer matrices that tends to control intake of water (Rohindra et al., 2004).

\section{Antimicrobial study}

Table 2 represents the zone of inhibition against the five different kinds of bacteria. The bacteria such as S. typhi, E. coli, $S$. aureus, $P$. aeruginoa, and $S$. mutans were examined against the hydrogel samples. Clear zone of inhibition adjacent to hydrogel indicates antibacterial activity. A higher antibacterial activity of the hydrogel is observed against E. coli, whereas lower activity is observed against the $P$. aeruginosa. Ciprofloxacin $5 \mu \mathrm{g}$ per disc was used as a reference standard and the obtained results were significantly comparable with the standard drug used (Cip $5 \mu \mathrm{g}$ ).

Significantly higher growth inhibitory effect on the Gram-negative bacteria (E. Coli) was evident when compared to the Gram-positive bacteria ( $S$. aureus and $S$. mutans). This is due to the fact that Gram-negative bacteria are far more susceptible to the water deficit caused by the fluid up-take than the Gram-positive

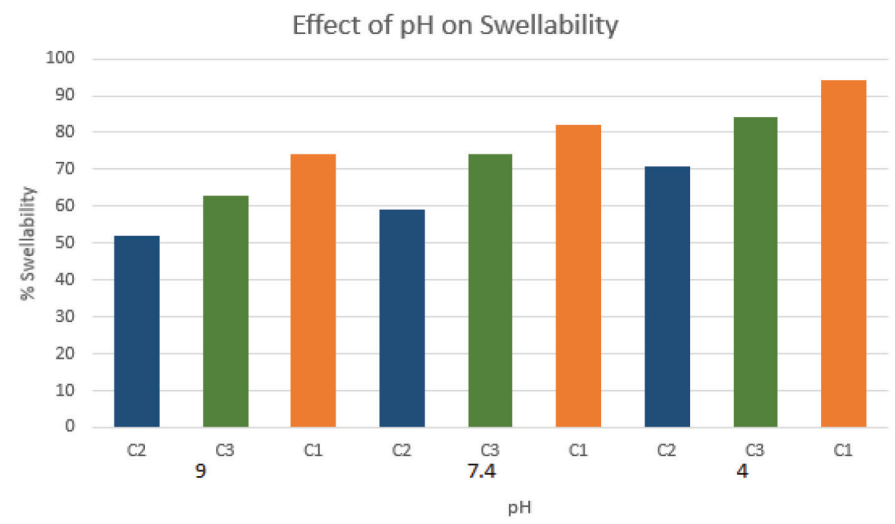

Figure 5. Effect of $\mathrm{pH}$ on percentage swelling. $n=3$, Values are mean $\pm \mathrm{SD}$ $p<0.05$.

Table 2. Antimicrobial activity of three different compositions of chitosan/PPP hydrogel.

\begin{tabular}{lccccc}
\hline $\begin{array}{l}\text { Microbial } \\
\text { strains }\end{array}$ & $\begin{array}{c}\text { ZOI of C1 } \\
\mathbf{m g} / \mathbf{m l} \\
(\mathbf{m m})\end{array}$ & $\begin{array}{c}\text { ZOI of C2 } \\
\mathbf{m g} / \mathbf{m l} \\
(\mathbf{m m})\end{array}$ & $\begin{array}{c}\mathbf{Z O I} \text { of C3 } \\
\mathbf{m g} / \mathbf{m l} \\
\mathbf{( m m}\end{array}$ & $\begin{array}{c}\text { ZOI of Ref. } \\
\mathbf{c o n t r o l} \\
\mathbf{C i p 5} \boldsymbol{\mu g}(\mathbf{m m})\end{array}$ & $\begin{array}{c}\text { Neg. } \\
\text { control } \\
\mathbf{1 0 \%} \\
\mathbf{D M S O}\end{array}$ \\
\hline E. coli & $28 \pm 1.5$ & $22.5 \pm 1.8$ & $25 \pm 0.9$ & $29 \pm 1.8$ & - \\
S. mutans & $25 \pm 1.6$ & $22.5 \pm 2.3$ & $20 \pm 0.7$ & $27 \pm 2.8$ & - \\
S. aureus & $19 \pm 0.9$ & $15 \pm 2.1$ & $18 \pm 0.5$ & $28 \pm 0.9$ & - \\
S. typhi. & $21.5 \pm 0.7$ & $15 \pm 2.6$ & $20 \pm 1.2$ & $20 \pm 2.1$ & - \\
P. aeruginosa & $17 \pm 1.3$ & $12 \pm 1.8$ & $15 \pm 1.5$ & $20 \pm 0.6$ & - \\
\hline
\end{tabular}

Values are the mean $\pm \mathrm{SD}$ of three independent replications $(n=3)$, ZOI $=$ Zone of inhibition, Cip $=$ Ciprofloxacin, DMSO = Dimethyl sulfoxide. bacteria. It is clearly observed that the formulation $\mathrm{C} 1$ showed higher zone of inhibition whereas the sample C3 and C2 showed higher activity only with respect to Gram-negative bacteria, such as $S$. typhi and P. aeruginosa. This may be due to the higher PPP content in $\mathrm{C} 1(0.15 \mathrm{~g})$ than that of $\mathrm{C} 2(0.075 \mathrm{~g})$ and $\mathrm{C} 3(0.10 \mathrm{~g})$.

From the published reports, it was evident that the antibacterial activity of PP was species dependent; the water extract of PP was effective against certain Gram positive and negative bacteria (Al-Weshahy and Rao, 2012). Prasad and Pushpa (2007) investigated the antimicrobial property of PP against different fungi and bacteria, the results indicated that the antimicrobial property of PP is species dependent and also it had noteworthy effect against $P$. aeruginosa and Clavibacter michigenensis when compared with the standard antibiotic, streptocycline (Prasad and Pushpa, 2007). The interaction between the positive charge of chitosan with negatively charged microbial cell membranes was responsible for its antimicrobial property and it was well established also (Venkatesan et al., 2014), which results in the osmotic imbalance and at the same time PPP demonstrates a synergistic effect which harms the cell membrane to direct the overall growth of the microbe, may be the probable mechanism of action.

The antibacterial activity and the exhibition of significant zone of inhibition by the chitosan/PPP hydrogel may be due to the presence of chitosan, whose antibacterial property is attributed to its cationic nature (Goy et al., 2009; Rabea et al., 2003) or the PP content which is rich in flavonoids, phenolic compounds and the glycoalkaloids which are toxic to the phyto-pathogens and helps in healing of wounds ultimately. Therefore, the results obtained in the present study indicated that the hydrogel formulations exhibited good antibacterial activity against the various Gram-positive and negative strains.

\section{CONCLUSION}

The usage of PP as a cheap and effective natural source to produce the chitosan/PP powder based hydrogel has been ascertained. The synthesized chitosan/PP powder-based hydrogel were subjected to a variety of characterization tests (FESEM, FTIR, swelling study, and antimicrobial study) which confirmed promising properties. It was established that the chitosan/PPPbased hydrogels exhibited antimicrobial properties and inhibited bacterial growth against various strains. Thus, the prepared hydrogel can be used as promoters for wound healing by inhibiting the microbial growth which are resistant to synthetic antibiotics and also it is used in antimicrobial drug formulations for the treatment of wound healing with further clinical evaluation.

\section{REFERENCES}

Akakuru OU, Isiuku BO. Chitosan Hydrogels and their glutaraldehyde-cross linked counterparts as potential drug release and tissue engineering systems - synthesis, characterization, swelling kinetics and mechanism. J Phys Chem Biophys, 2017; 7(3):1-7.

Al-Weshahy A, Rao VA. Isolation and characterization of functional components from peel samples of six potatoes varieties growing in Ontario. Food Res Int, 2009; 42:1062-6.

Anicuta SG, Loredana DM, Stroescu M, Iuliana J. Fourier transform infrared spectroscopy (FTIR) for characterization of antimicrobial films containing chitosan. Analele UniversităNiii din Oradea Fascicula: Ecotoxicologie, Zootehnie şi Tehnologii de Industrie Alimentară, 2010; 1234-40. 
Basualdo C, Sgroy V, Finola MS, Juam M. Comparison of the antibacterial activity of honey from different provenance against bacteria usually isolated from skin wounds. Vet Microbiol, 2007; 124(3-4):375-81.

Billiet T, Vandenhaute M, Schelfhout J, van Vlierberghe S, Dubruel P. A review of trends and limitations in hydrogel-rapid prototyping for tissue engineering. Biomaterials, 2012; 33(26):6020-41.

Bodner JM, Sieg J. Ingredients in meat products. In: Tarte R (ed.). Properties, functionality and applications, LLC, Springer Science. Business Media, New York, NY, pp 83-109, 2009.

Chai Q, Jiao Y, Yu X. Hydrogels for Biomedical applications: their characteristics and the mechanisms behind them. Gels, 2017; 3(4):115.

Daniele MA, Adams AA, Naciri J, North SH, Ligler FS. Interpenetrating networks based on gelatin methacrylamide and PEG formed using concurrent thiol click chemistries for hydrogel tissue engineering scaffolds. Biomaterials, 2014; 35(6): 1845-56.

Friedman M, Lee K-R, Kim H-J, Lee I-S, Kozukue N. Anticarcinogenic effects of glycoalkaloids from potatoes against human cervical, liver, lymphoma and stomach cancer cells. J Agric Food Chem, 2005; 53(15):6162-69.

Furuike T. Preparation of chitosan hydrogel and its solubility in organic acids. Int J Biol Macromol, 2017; 104:1620-25.

Goy RC, Britto D, Assis OBG. A review of the antimicrobial activity of chitosan. Polímeros, 2009; 19(3):241-7.

Hoffman AS. Hydrogels for biomedical applications. Adv Drug Deliv Rev, 2012; 64:18-23.

Levy SB, Marshall B. Antibacterial resistance worldwide: causes, challenges and responses. Nat Med, 2004; 10:122-9.

Mah TF, O' Toole GA. Mechanisms of biofilm resistance to antimicrobial agents. Trends Microbiol, 2001; 9(1):34-9.

Mandal S, Deb Mandal M, Pal NK, Saha K. Antibacterial activity of honey against clinical isolates of Escherichia coli, Pseudomonas aeruginosa and Salmonella enterica serovar Typhi. Asian Pac J Trop Med, 2010; 3(12):961-4.

Mandal S, Deb Mandal M, Pal NK. Synergistic antiStaphylococcus aureus activity of amoxicillin in combination with Emblica officinalis and Nymphae odorata extracts. Asian Pac J Trop Med, 2010; 3(9):711-4.

Mandal S, Pal NK, Chowdhury IH, Deb Mandal M. Antibacterial activity of ciprofloxacin and trimethoprim, alone and in combination, against Vibrio cholerae O1 biotype El Tor serotype Ogawa isolates. Pol J Microbiol, 2009; 58(1):57-60.
Othman SH, Edwal SAM, Risyon NP, Basha RK, Talib RA. Water sorption and water permeability properties of edible film made from potato peel waste. Food Sci Technol, 2017; 37(1):63-70.

Prasad AGD, Pushpa HN. Antimicrobial activity of potato peel waste. Asian J Microbiol Biotechnol Environ Sci, 2007, 9(3):559-61.

Rabea EI, Badawy MET, Stevens CV, Smagghe G, Steurbaut W. Chitosan as antimicrobial agent: applications and mode of action. Biomacromolecules, 2003; 4:1457-65.

Rohindra DR, Nand AV, Khurma JR. Swelling properties of chitosan hydrogels. South Pacific J Nat Appl Sci, 2004; 22(1):32-5.

Saga T, Yamaguchi K. History of antimicrobial agents and resistant bacteria. Jpn Med Assoc J, 2009; 52(2):103-8.

Sahoo D, Sahoo S, Mohanty P, Sasmal S, Nayak PL. Chitosan: a new versatile bio-polymer for various applications. Des Monomers Polym, 2012; 12(5):377-404.

Schieber A, Marleny D, Aranda S. Potato peels: a source of nutritionally and pharmacologically interesting compounds - a review. In: Teixeira da Silva JA (ed.). Food, Global Science Books, Japan, 2009.

Sepelev I, Galoburda R. Industrial potato peel waste application in food production: a review. Res Rural Dev, 2015; 1:130-6.

Venkatesan J, Jayakumar R, Mohandas A, Bhatnagar I, Kim SK. Antimicrobial activity of chitosan-carbon nanotube hydrogels. Materials, 2014, 7:3946-55.

Wang T, Jiao Y, Chai Q, Yu X. Gold nanoparticles: synthesis and biological applications. Nano LIFE, 2015; 5(3):1542007.

Yu X, Chen X, Chai Q, Ayres N. Synthesis of polymer organogelators using hydrogen bonding as physical cross-links. Colloid Polym Sci, 2016a; 294:59-68.

Yu X, Jiao Y, Chai Q. Applications of gold nanoparticles in biosensors. Nano LIFE 2016b; 6(2):1642001.

How to cite this article:

Neha K, Anitha R, Subashini R, Natarajan A, Sridhar TM. Synthesis and characterization of chitosan/potato peel powder-based hydrogel and its in vitro antimicrobial activity. J Appl Pharm Sci, 2019; 9(09):066-071. 